[This paper will appear as a book chapter in: Brighenti, Andrea Mubi (Ed.) “The New Politics of Visibility”; published by Intellect Books in 2022.]

\title{
Open Science as an Engine of Anxiety: How Scientists Promote and Defend the Visibility of Their Digital Selves, while Becoming Fatalistic about Academic Careers $^{1}$
}

\author{
Martin Reinhart \\ Humboldt-Universität zu Berlin \\ martin.reinhart@hu-berlin.de
}

\section{IN T R O D U C T I O N}

Science, as a professional field, produces extreme forms of inequality. Most young and aspiring scientists who sucessfully complete their tertiary education and go on to train as a $\mathrm{PhD}$ or doctoral student, never make it to becoming a 'working scientist'. Most of those who do become postdocs, never make it to becoming a tenured professor. And most of those who become professors, never make it to becoming famous in their field, receiving prestigeous prices or even being highly cited. Careers in science are a trial of attrition, where only the best (or the luckiest?) prevail in the competition for careers. Scientists themselves tend to believe, generally, that science is a meritocracy, with the most productive being selected along these career junctures. While there is no logical contradiction between meritocracy and competitivity and while many scientists believe that the meritocratic

\footnotetext{
${ }^{1}$ As always, I learned a lot for this paper from numerous discussions with colleagues at the Robert K. Merton Center for Science Studies. For in-depth discussions and specific comments I am specifically grateful to Tim Flink, Stephan Gauch, Barbara Hendriks, Felicitas Heßelmann, Stefan Hornbostel, and Cornelia Schendzielorz. A special thank you goes to Andrea Mubi Brighenti not just for helpful comments to the paper but also for putting together this volume in a equally professional and enjoyable way. The remaining flaws of the paper are all mine.
} 
ideal explains and justifies the high competitivity sufficiently, there is at least some ambivalence. Robert K. Merton (1973) noted the general ambivalence that results from the interplay between the normative structure and the reward system in science. Since then it is not just the increased competitivity and the rising inequalities, that have changed; more importantely, it is the way visibility regimes have been changing over the last 20 years, mainly due to digital communication, that has forced scientists to acknowledge the ambivalence inherent in the meritocratic narrative. This essay is an attempt to explore this ambivalence, which, as of yet, has no ready-made description.

A first way of describing this ambivalence may start from a series of first-person accounts, empirical research results, and theoretical insights, that come from an emerging literature on the subject. Science as an "engine of anxiety” (Espeland and Sauder, 2016; Fochler, Felt and Müller, 2016), “imposter syndrome” (Loveday, 2018; Grey, 2020; Keogh, 2020), “publishor-perish” (Dalen and Henkens, 2012; Rijcke et al., 2016), or just "ambivalence" (Flink \& Simon 2014) are some of the terms used to describe a perceived shift in research cultures, where meritocracy and competitivity have lost balance. This literature refers to processes of quantification (Desrosières, 1998), medialization (Weingart, 1999), projectification (Torka, 2009, 2018; Franssen et al., 2018), or to significant shifts from block funding to temporary and third-party-funding. The result of these overlapping and sometimes mutually reinforcing processes is felt by individual researchers as a source of anxiety, leading to feelings of inadequacy, and, ultimately, to the belief that science may be more of a lottery than a meritocracy (Loveday, 2018; Reinhart and Schendzielorz, 2020). It is easy to dismiss these feelings as the reactions of those who have lost out in the competition for recognition. That would, however, be premature for two reasons. First, these feelings may still be a reaction to a shift in research cultures, irrespective of whether this reaction is deemed adequate or not. Second, these feelings and beliefs have become a relevant force in movements and policy initiatives that push for such diverse goals as more reproducibility of research results, more gender equality and diversity in academia, or more careful use of quantitative indicators in the (selfgovernance of science. ${ }^{2}$

To address these issues, my argument in this essay will ,first, describe the ambivalence in a current understanding of science both as competitive and meritocratic, by relating it to changes in scientific visibility regimes. Second, I will briefly discuss the theoretical concepts that emerge from such a description, mainly 'visibility', 'background emotions', and 'digital selves'. Third, I will lay out one strategy that highly visible individual scientists seem to employ, to deal with the ambivalence of these new visibility regimes. Finally, forth, I will discuss what the ensuing politics in science might be, that result collectively from such individual strategies. The argument will result in a paradox: The current visibility regime in science,

\footnotetext{
${ }^{2}$ As always, the Thomas theorem applies: "If [people] define situations as real, they are real in their consequences.” (Thomas and Thomas, 1928, p. 572)
} 
resulting from digital communication and online platforms, leads to excitement among scientists over the possibilities for attaining hypervisibility. Increasingly, however, the excitement of fashioning digital selves is taken over by anxiety over being exposed to the possibility of negative, reputation threatening attention. Pardoxically, anticipating and preventing such a possibility leads to even more vigorous fashioning of digital selves, for which the open science movement provides the most suitable policy narrative. In short: to protect themselves from the possible negative effects of visibility, scientists push for more visibility; while becoming fatalistic about their careers and about science policy.

Hypervisibility in SCIEnce - A Caricature OF THEN AND NOW

The belief that science is a meritocracy, albeit an imperfect one, is one way of justifying stark hierarchies and inequalities. That there actually is a highly skewed distribution of recognition and power in science can be illustrated by the extreme selectivity along career paths, as I have done above. Another is to highlight publication and citation patterns, where the pervasiveness of power law distributions is undeniable (Kim et al., 2020). Of those scientists that publish any research, only few produce a high number of publications over their careers, while most of the others are part of the 'long tail' with just a few publications. The recognition of these publications in the form of citations is similarly skewed. While only very few publications receive high numbers of citations, most of the others are part of the long tail, where a sizeable number is never cited at all. Whenever highly skewed distributions of recognition are acknowledged, a need for explaining or justifying them arises.

For a long time, such disparities were explained and justified by invoking the idea of genius. Those who made it to the very top of these hierarchies were seen as capable of research in a way that the others were not. This aristocratic ideal fit the empirical reality of steep hierarchies and power law distributions of recognition rather well. Even though the idea of genius is still sometimes invoked, especially in popularizing discourse, it has lost most of its plausibility. More egalitarian, meritocratic ideals have taken over from the second half of the $20^{\text {th }}$ century on. ${ }^{3}$ With this shift, however, the problem that Merton (1968) termed 'the phenomenon of the 41st chair' became more prevalent. The name derives from the French Academy limiting the number of its prestigious chairs to 40 and thus producing 'infamous' holders of the non-existant $41^{\text {st }}$ chair, such as Descartes and Pascal (Merton, 1968, p. 56). I argue that, while the phenomenon may seem like a 'luxury problem' for only the most elite scientists, e.g. of those being

\footnotetext{
${ }^{3}$ This is not to say that genius and meritocratic narratives are mutally exclusive or that meritocratic ideals have no relevance before the $20^{\text {th }}$ century; both are clearly not the case. It is just to say that there is a discernable shift in narratives about science that emphasizes meritocracy and deemphasizes genius.
} 
omitted for a Nobel prize, it has actually become a more generalized issue. For most scientists it has become apparent that the distribution of recognition is very different from the distribution of quality, and not just at the top. Most will attest to the idea that the capability of individual researchers to perfom good research is more evenly distributed than the steep power hierarchies would suggest. Similarly, most will attest to the idea that quality in the published literature is more evenly distributed than the citation numbers would suggest. There is a disconnect between the hypervisibility of success and the overall level of quality in science, much like in the star-systems in popular culture, e.g. in acting or music (Haampland, 2017).

The impression of a disconnect between quality and recognition has taken hold in the context of new visibility regimes. The phenomenon of the $41^{\text {st }}$ chair belongs to a time, when it was just a few individual scientists for whom their (hyper)visibility became an issue. Robert Boyle is a famous example, when he complained his scientific work would not receive enough critical feedback because of his prominent political and religious standing (Shapin, 1994, p. 126ff). In our times, visibility has become an issue every scientist has to be concerned with, irrespective of his or her position. The following caricature of science then and now may help to make that point: the shift to primarily digital forms of communication fundamentally changed the visibility of individual scientists.

Before the $21^{\text {st }}$ century, the average scientist was visible primarily as an author of scientific publications, with their name and their institution (rarely with a short biographical note). In addition, the occasional conference, talk, and job application, where one could present oneself in person, reached a very limited audience outside one's immediate work environment. And that was it. Visibility through authorship tied the reputation of scientists almost exclusively to the communicated results of their research in the form of academic papers and books. Now, with the advent of digital forms of communication, even the average scientist is permanently visible in numerous contexts. Their digital selves appear as personal and institutional websites, on social media platforms (e.g. more academically oriented on Google Scholar or more publically oriented on Twitter), or in videos from conference talks. That new visibility through digital selves comes in addition to authorship visiblity from academic publications. However, authorship visibility is now linked to digital selves elsewhere (e.g. through orcid.org). Inherent to these digital selves and platform cultures are a flurry of metrics: citations, views, downloads, reads, likes, retweets, etc; What these metrics do is making the attention for digital selves visible to themselves and to everyone else. Visibility through digital selves ties the reputation of scientists increasingly to sheer activity and selffashioning on digital platforms, irrespective of whether these are connected to academically communicated research in a meaningful way. The main difference between visibility then and now is that authorship visibility is 
intermittent and strongly tied to the results of academic work, while digital selves are permanently visible and only weakly tied to academic work.

Two possible consequences of this will be important for my further argument: first, scientists have become acutely and (through metrics) precisely aware of how visible they are, and, second, despite the considerable work that goes into the fashioning of digital selves, scientists feel less in control of their visibility. On this basis, the idea that science is both highly competitive and meritocratic becomes more difficult to maintain. Not because it would be less true that science still is both, but because scientists now have more narratives at their disposal to explain individual career success. Max Weber, in "Science as Vocation" (Weber, 2002), famously advised young scientists to brace for the likely frustration that less competent competitors will surpass them career-wise. ${ }^{4} \mathrm{He}$ alludes to at least two counter-narratives to meritocratic success, which both are deemed problematic: success based on favoritism and success based on popularity (with students). While both narratives are difficult to align with meritocratic scientific ideals, they were generally seen as in the realm of the illegitimate or even illegal. What has changed in the present is that success by popularity is now mostly seen as non-detrimental to scientific work. ${ }^{5}$ Career advice to young scientists even regularly includes the suggestion to popularize a digital self. Before I can argue how this drives a wedge of ambivalence between competition and meritocracy, I take stock of the central concepts needed for this argument.

\section{Visibility, Digital Selves , And Background EMOTIONS}

In line with the common themes of this volume, the concept of visibility provides the primary issue through which the argument in this essay is framed. The field of modern science offers two additional reasons to emphasize visibility. First, scientific cultures are in central epistemic aspects primarily visible cultures. Ideals of objectivity and research practices, even though they change over time and differ across disciplines, center around focussing scientific attention on obscure or as of yet invisible aspects of the world and convincing others of their factualness by making them visible (Daston, 2000; Daston and Galison, 2007). Experimental practices, such as photography, microscopy, or measurement, rely on the eyes of scientists and the primarily physiological act of seeing to verify scientific facts (Daston

\footnotetext{
4 "Glauben Sie, daß Sie es aushalten, daß Jahr um Jahr Mittelmäßigkeit nach Mittelmäßigkeit über Sie hinaussteigt, ohne innerlich zu verbittern und zu verderben?" (Weber, 2002, p. 481).

${ }^{5}$ Whether favoritism is still seen as mainly illegitimate is less clear. Blinding and dealing with conflicts of interest in peer review has become a more serious concern, confirming that favoritism is still deemed illegitimate. However, career advice and expectations emphasize acitvely building an academic network to profit from the „strenght of weak ties“ as an of course. That such networks produce more than just epistemic benefits is implied at least. (Böhler and Reinhart 2014).
} 
and Galison, 2007), while more literary practices, such as statistics, graphics, "virtual witnessing" (Shapin and Schaffer, 1985), or "intersubjective understanding" (Bezzola Lambert, 2016) rely on more abstract forms of visualizing. Second, scientific cultures are in central social aspects visible cultures, because reputation plays a paramount role in assigning status and truthfulness to individual researchers and institutions (Shapin, 1994). The scientific reward system (Merton, 1973, p. 281ff) and credibility cycles (Latour and Woolgar, 1986) are the processes through which the images of scientists are formed and converted into status or more mundane resources such as funding, jobs, or research materials.

These two forms of scientific visibility, epistemic (objectivity) and social (reputation), are not equally affected by the story above of how science has changed. The change in social visibility over the last 30 years is more pronounced than in epistemic visibility. I referred to the cause for this differential change as the "shift to digital forms of communication". This is just a clumsy way of saying that visibility regimes have changed in general, without referring to one of the many concepts for this change that have been proposed in the literature. With respect to visibility, Foucaults description of the panopticon remains of relevance (Foucault, 1977), albeit without the heavy emphasis on centralized forms of social control (Garland, 1986). Especially the visibility of scientists is more aptly described as a form of “decentralized panopticism” (Maasen and Sutter, 2016), where the productive aspects of openness and disciplinarity are frequently emphasized by the scientists themselves (see e.g. the current discourse on open science). "As much as the individual is under (self-)surveillance, it operates as a telematic subject continuously controlling and creating subjectifying interactions from a distance" (Maasen and Sutter, 2016, p. 175). Besides the heightened visibility in general, the aspects of "hypervisibility" (Brighenti, 2010, p. 47) or "media-type visibility" (Brighenti, 2007, p. 339; Thompson, 2005) are relevant also. As described above, extreme forms of visibility associated with star systems and power law distributions of attention may have been exclusive to the likes of Nobel prize winners in earlier times (Zuckerman, 1967); today, they have relevance for average scientists also. Crucial for my argument is that "media-type [visibility] tends to work according to a flash-halo mechanism, whereby subjects are isolated from their original context and projected into a different one endowed with its own logic and rules" (Brighenti, 2007, p. 339).

With respect to individual scientists, it is no longer adequate to think of their visibility as primarily based on authorship. Much like anywhere else, digital platform culture makes scientists visible as "digital selves" (Luppicini, 2012; Lovink, 2014) and the work that builds and maintains these selves are forms of "self-fashioning" (Greenblatt, 1980; Knights and Clarke, 2013). This work consists, on the one hand, in constantly updating these digital selves, whenever something deemed relevant can be added, such as a new publication or a new place of work, but also down to 
minimalia such as the planned date of arrival at a scientific conference via Twitter. These forms of presenting and promoting oneself, with or without self-awareness, are bound up in permanent feedback loops of comparing different digital selves (one's own and those of others) either by actually looking at them individually or by using the many platform metrics to sort and compare. And since both these selves and the metrics are constantly visible to others, self-fashioning becomes a treadmill-like activity. The visibility 'invites' to work at one's digital self, the comparison with others 'invites' to refine that self accordingly, and the metrics 'invite' to outperfom the others or a former self; and since these metrics are sensitive to the sheer quantity of activity on these platforms, self-fashioning seems to work, as the numbers go up. However, the numbers of the others do also go up. It would be easy to denounce such processes as fetishization or hypercompetitivity, however, that would require to take my caricature of then and now too seriously and would proclaim an earlier situation as somehow better than the present one. I would like to stay as far from such a nostalgic position as possible, as my interest lies in understanding how scientists might feel about this situation, how they might act upon it, and what type of politics might result from their action, collectively.

The terminology surrounding descriptions of the current state of science as 'an anxiety machine' or as 'publish or perish' make it clear that scientists feel different about the current balance between meritocracy and competitivity, and we should, thus, capture some of the emotional aspects of the new visibility regimes (e.g. Hearn, 2008, p. 190ff; Gabriel, 2010). Barbalet (2004, p. 59f) has suggested to describe feelings that pertain to social structures and not just to specific situations as "background emotions”. In science, Barbalet raises the question as to how background emotions are instrumental to ideals of objectivity or rationality and provide scientific motivation in general. "At the individual level, such a question is practically devoid of meaning because the personal motives involved will be as numerous as the numbers of persons implicated, indeed more numerous, as most individuals relate to goals with multiple motives. Yet consideration of whether emotions in science are associated with a 'hedonistic-libertarian' or an 'ascetic' ethos is not entirely without purpose" (Barbalet, 2004, p. 145). What the diagnoses of increasing numbers of scientists who feel fatalistic about their career success or who suspect that they will soon be found out as not deserving scientists ('impostor syndrome') could indicate, is that trust in science as a productive and just professional system, trust as a background emotion, is diminishing. I suggest that this raises the question as to how scientists try to regain some of this trust through individual action.

Diminishing Trust, Anxiety, And FAtalism AS BACKGROUND EMOTIONS 
The trust of scientists in science as a well-functioning system is predicated on the belief that competitivity and meritocracy mutually reinforce and balance each other. Competitivity drives scientists to produce new and original claims of facts and theories, while meritocracy ensures that the validation of these claims and the rewards for scientists are allocated according to scientific quality criteria and through legitimate procedures (e.g. peer review). However, almost no one really believes in such a Panglossian view of things, as stories about papers being rejected by the notoriously biased 'reviewer two' or job applications resulting in a less qualified colleague being hired are everywhere. Even beyond such anecdotal evidence, the results from research, that show peer review to be more biased, less reliable, and less valid than generally expected, have become widely accepted (Reinhart and Schendzielorz, 2020). The result, however, has not been a fundamental disbelief in the meritocratic aspects of science, but a “passive acceptance” (Giddens, 1990, p. 83ff) or "systems trust” (Luhmann, 2000) of a meritocratic system as flawed, but still better than the alternatives. The question whether that Churchillian view of 'not ideal but better than the alternatives' is a sign of an almost unshakeable belief in science as a wellfunctioning system, or, contrarily, a sign of such a belief becoming increasingly fragile, marks the crossroad for my further argument. I will emphasize the fragility of this view, and engage in a thought experiment as to where this fragility might lead to as science politics ${ }^{6}$.

I am going down this path as a result of my research over the past few years on peer review, scientific misconduct, and biomedical translation. Even though the Churchillian view has been a frequent narrative for a long time, both in the literature on peer review and in interviews with scientists (Reinhart, 2012; Reinhart and Schendzielorz, 2020), the surrounding narratives on the general quality of scientific research have become more sombre. A good place to start is the debate in biomedicine about 'translation', where scepticism has been rising about the efficacy and efficiency of basic research resulting in new or improved drugs and therapies (Blümel et al., 2015). As a result, the overall quality of research has become a widely problematized issue, with a paper (unironically) titled "Why most published research findings are false” (Ioannidis, 2005) as a conspicuous focal point. The conspicuosness lies in the fact, that most commentators seem to agree that a majority of experimental research performed in biomedicine is subject to (mostly trivial) methodological flaws. As a consequence, scientists are beginning to form new narratives to make sense of this perceived state of affairs. One such narrative that came up in interviews with biomedical researchers was, first, blaming the infatuation in science policy with excellence and, then second, demanding more support for 'average' scientists (Hendriks, Schendzielorz and Reinhart, 2018); a clear example of a narrative

${ }^{6}$ In this sense, my argument is biased and the reader might be well advised to engage in some adversarial reading in what follows. I have provided evidence and arguments for such an adversarial reading, with special emphasis on peer review, elsewhere: Reinhart (2012), Schendzielorz \& Reinhart (2020), Reinhart \& Schendzielorz (2020). 
fundamentally problematizing competitivity and meritocracy in science (see also below).

Similarly, and not surprisingly, the discourse on scientific misconduct is fraught with narratives problematizing the quality of research. Three of these narratives are relevant here. First, individual perpetrators are seen as morally unfit scientists ('bad apples'). Second, whole groups are seen as a threat to the moral fabric of science and are, thus, stigmatized; postmodernism or researchers from non-western countries are frequent targets for such labelling (Hesselmann, 2018b, 2018a). Third, there is a generalized notion of systemic issues that decrease the overall quality of research; not unlike the Ioannidis example above (Hesselmann et al., 2017; Hesselmann and Reinhart, 2019, 2020). In addition, a general level of unease, anxiety, and even fear is palpable when the subject turns to accusations of misconduct and of a resulting loss of reputation, irrespective of the justifiability of such accusations. The threat of such emotions can be directed at the (institutional) self, when e.g. universities, funders and journals build up 'rationality facades' of compliance rules and codices to prevent reputation loss. It can also be outward directed at science in general, e.g. when replication initiatives are seen as an incentive for less visible scientists to attack highly visible ones with 'cheap shots' (Reinhart, 2016). The palpable anxiety inherent in such discourse is further reason to examine the fragility of the Churchillian view.

If trust as the emotional background for how scientists view their own work environment is diminished because meritocratic ideals have become more difficult to uphold, then, the shift to decentralized panopticism may add further instability. These two challenges to trust are, however, qualitatively different. While the former presupposes that meritocracy is still a desireable ideal and just needs to be strenghtened, the latter produces ambivalence and may end up with a view that sees both ideals, meritocracy and competitivity, as deeply problematic and not desirable for science. While the Churchillian view is the reaction to partial criticism of meritocracy, i.e. organized scepticism, i.e. peer review, the reaction to the star systems of decentralized panopticism may be a more fatalistic form of disillusion. At least that is what the talk about 'anxiety machines', 'publish or perish', and 'impostor syndrome' seems to suggest: an emotional shift from systemic trust to insecurity and anxiety. Some loss of trust should be expected to go along with all structural changes, such as those with decentralized panopticism and digital selves, and the conservative expectation would be that this loss is only temporary, as a new generation of scientists comes along, socialized into the new regime. Contrary to this, my claim here is that the ambivalence resulting from decentralized panopticism is already undermining socialization of younger scientists.

Vik Loveday (2018) has argued, that academic identities are increasingly fraught with feelings of anxiety and the sense of being out of 
control. Her research shows that this is especially the case for younger and “casualized academic employees” (Loveday, 2018, p. 760), i.e. non-tenured faculty. Their lived work experiences produce a conspicuous narrative, where the success of others is explained by them having done good work, while one's own success is explained by luck. Accordingly, the failure of others is attributed to unfortunate circumstances, while one's own failures are attributed to one's own deficiencies. Even though her argument ties this primarily to fixed-term employment; stress, anxiety, pressure to perfom and increased competition are prevalent in the whole of academia, affecting the well-being not just for casualized employees (Loveday, 2018, p. 759). That a narrative of luck or chance has become relevant in making sense of career trajectories is a strong indication that meritocratic ideals, indeed, have lost their shine. While Loveday draws the valid conclusion that such narratives "are indicative of the academics' diminished agency" (Loveday, 2018, p. 762) especially in the context of the so-called neoliberal university and especially in Great Britain. I would like to generalize such an argument for the wider context of science as a decentralized panopticon.

\section{Anticipating 15 Minutes OF FAME}

Through a series of examples my aim in this section is to, first, reinforce the claim that the (negative) aspects of visibility, formerly only relevant for the most highly visible scientists, have become generalized issues. Second, I will highlight one type of reaction from scientists to these issues, that I call the 'covering all your digital bases strategy', that might push platform cultures and decentralized panopticism even further.

The high visibility of the most successful scientists always had aspects, that were seen as negative. I mentioned Robert Boyle's immunity from criticism as a result of his fame, above. Historically closer are the Nobel Prize winners that Harriet Zuckerman interviewed in the 1960s, reflecting on the changes that were brought on by their immense success: “[...] we have gone from zero to the condition of movie stars. We have been submitted to what may be called an ordeal. We are not used to this sort of public life which has made it impossible for us to go on with our work, [...] Our lives are completely upset. [...] When you have organized your life for your work and then such a thing happens to you, you discover that you are faced with fantastic new responsibilities, new duties" (Zuckerman, 1967, p. 399). The social obligations that come with receiving such a prestigeous prize are felt as burdensome and a decline in productivity can be the result of wanting to fulfill these additional obligations. So, even in the situation of being highly visible for something that is generally seen as good and desireable, and without any public criticism, hypervisibility entails pressures that are felt as anxiety. 
Today's average scientists may be a lot more visible through (digital) media than their predecessors 30 years ago, but they are still far from experiencing the flash and halo of attention that go along with winning a Nobel Prize. The way they are fashioning their (average) digital selves, however, show the anticipation of similar obligations and pressures as are part of the halo of a prestigious prize. Instead of colleagues and the media requesting honorary talks, interviews, etc., now it is digital platforms constantly requesting activity from digital selves. On the one hand, these platforms generate a large amount of requests for uploading papers, responding to queries, updating profiles, etc., because the success of these platforms is predicated on the amount of activity on them. On the other hand, these digital selves create obligations without platforms explicitly requesting any, because scientists do not want to be seen as inactive and, thus, engage in constant self-fashioning. All of this happens under the presumption that there is actually somebody watching, but, by now, most scientists will have realized that it is mostly the platforms and their algorithms that are watching.

It is reasonable to expect that most of the self-fashioning of digital selves will become, or already is, purely instrumental, in a sense that some have begun calling 'gaming the indicators' (Rijcke et al., 2016). It is in the same way that Sauder \& Espeland (2009) have shown that publicized rankings of higher education organizations lead individual members to have highly ambivalent feelings. Participation in rankings is seen as purely instrumental and as an unavoidable burden, while simultaneously being proud or disappointed in the case of good or bad ranking positions, respectively. Such constellations can become to be felt as alienating, or as a source of anxiety. In the case of digital selves, such anxiety comes from two sources of visibility, or better, two sources of attention based on decentralized panopticism. The attention from platforms and indicators can be a constant source of anxiety, as well as the real possibility that someone could actually be watching, maybe even someone responsible for a hiring decision. As a consequence, the fashioning of these digital selves has to work for both types of visibility: it has to ensure that the indicators go up through activity and it has to provide an impeccable self in case somebody is actually watching.

For individual scientists the question arises, how to fashion individual selves that work well when subjected to both types of visibility. Brighenti (2007) calls the two "media-type" and "control-type" visibility: "The mediatype [...] tends to work according to a flash-halo mechanism, whereby subjects are isolated from their original context and projected into a different one endowed with its own logic and rules. [... T] he control-type transforms visibility into a strategic resource for regulation (as in Foucault's surveillance model) or selectivity and stratification (as in Deleuze's society of control model), or both (as in Haggerty and Ericson's surveillant assemblage)" (Brighenti, 2007, p. 339). It would seem that self-fashioning should differ as a reaction either to control-type or to media-type visibility. 
Control-type visibility elicits self-fashioning that either shows selves to be normal (when control is felt to be punishing for deviance or underperformance) or overperforming (when control is felt to be rewarding overperformance). Due to the skewed distribution of recognition in science, normalizing a digital self is never good enough, as average performance always seems closer to the bottom than the top (Brighenti, 2019). ${ }^{7}$ Mediatype visibility, in contrast, elicits self-fashioning that either shows selves that can attract flash-halo-type attention in case the attention is positive (e.g. a prize) or diffuse such attention in case it is negative (e.g. accusation of misconduct). Besides the fact that media-type visibility generally requires comparatively simple narratives (e.g. the genius narrative, or now, the most cited narrative), it calls for normalized selves in case of negative attention and excellent selves in case of positive attention. Subjected to media-type and control-type visibility simultaneously, scientists cannot use a simple strategy, such as just maximizing the indicators, but have to cope with these ambivalences in fashioning their digital selves.

\section{COVERING ALL YOUR DIGITAL BASES}

What follows is an exaggerated and one-sided story with the purpose of emphasizing a particular point. The point being, to provide an abstracted first-person view of such a visibility regime, by imagining how scientists move from seeking visibility mainly through the authorship of publications directed at colleagues in their field to seeking visibility through the fashioning of digital selves. The resulting story exaggerates the linearity of such an account, as individual researchers need not move through these steps in sequence nor need they move through all of them. A further exaggeration is the level of agency implied in this narrative, as I would not like to assume that how scientists seek visibility is either completely passive or active, is either coerced or voluntary, or is either dreaded or embraced. Irrespective of whether some believe that it is their own choice to be an entrepreneurial scientists in an open and digital age or whether some believe that they are forced to abandon a traditional and proven form of academic work, my goal is to make the outcome of this story an understandable emotional result for many, who either exit science, live with 'impostor syndrome', or cope with some other strategy.

How might we imagine that scientists are pushed or lured away from a regime of authorship visibility? The first step, like all of them seeming innocuous, begins with the realization that doing good research and publishing it in a suitable journal or book is not enough. With so much research being published, dissemination is a next necessary step: You need to

\footnotetext{
${ }^{7}$ Evaluative scientometrics co-evolved with this development by recommending indicators that are robust to skewed distributions, instead of averages which are not, e.g. only counting papers that are in the top $10 \%$ of being cited.
} 
put additional work into drawing attention to your published research! Digital selves provide ample opportunity for such work. Information about newly published work can be shared e.g. as a byline to all sent email, as a tweet, or as an upload to the myriad of scientific platforms. While publishing academic work is selective - you are looking for the right/best journal or publisher - dissemination is broad - the more places, where your published work is mentioned, the better. It is not enough, however, to disseminate through every available platform, as this alone is not very effective in drawing attention. An academic Twitter account that is just mentioning one's own papers is unlikely to generate 'followers'. Dissemination, as a second step, must be tied to digital selves that are more active; in the case of Twitter this means maintaining a platform profile that tweets regularly and interacts with others on a diverse set of (academic) issues. The imperative to disseminate widely leads to the fashioning of multiple digital selves. Maintaining an active presence on multiple platforms can, then, quickly become time consuming, e.g. because much of the communication must be both timely and regular or because multiple digital selves elicit the question of how they fit together within an overall academic profile and, thus, more work is needed to integrate multiple digital selves. The issue of how you disseminate your research quickly becomes an issue of fashioning digital selves, which are less directly tied to the specific results of one's research.

It is not necessarily the case, that these two steps are felt by researchers to be the result of a form of controlling or "surveillant visibility" (Brighenti, 2010, p. 148ff). Many, if not most, scientists are intrinsically motivated to disseminate their research beyond just publishling scholarly literature and believe that this is an integral part of scholarly communication. It is also safe to assume that the number of scientists who feel the same about the fashioning of digital selves is smaller. Nonetheless, there is a sizeable number to whom the fashioning of digital selves is a seductive activity, which allows for more than just effective dissemination. It can also be a way of communicating with colleagues, finding new colleagues, developing new ideas, or satisfying a personal urge for recognition. Where, however, a definite controlling aspect comes into these steps is in career opportunities. Applications for individual career grants increasingly ask for information of past or planned dissemination activities and require digital selves, e.g. on orcid.org. It seems that the increase in third-party funding and the decrease in the success rate for funding applications has led to ever more such secondary quality criteria being requested and used in funding programs. The same is true for performance indicators such as number of publications, number of citations, cumulative impact factor, h-index, or altmetric scores.

Putting work into increasing the value of performance indicators is, thus, the next step. Again, the controlling aspect of performance indicators may be felt most vividly in the case of funding applications, hiring procedures or institutional evaluations, where the usage of such indicators 
has become widespread. In fashioning digital selves, indicators can be seductive, when rising numbers of retweets, follows, downloads, citations, etc. become a form of self-affirmation that may also be interpreted as recognition. The opposite is also possible, when playing the indicator game leads to feelings of emptiness and disappointment, because the interaction with platforms and indicators becomes meaningless compared to actual research or interaction with colleagues. Irrespective of whether indicators are felt to be controlling and disciplining or enticing and self-affirming, they reinforce competitiveness either with one's own self or with others. The general expectation is that surveillant visibility enforces forms of behavior that are seen as normal or average. In the scientific context, however, where competitiveness is already high and where recognition and rewards follow an extremely skewed distribution, surveillant visibility pushes individual behavior past the goal of average to the goal of excellence. Digital selves need to distinguish themselves from others (as the orcid slogan so clearly states). ${ }^{8}$

The need to be distinct, above average, or excellent moves the visibility regime towards the media-type. Digital selves move from being fashioned to achieve more effective dissemination to having qualities that can catch a flash and halo. So the next step for individual scientists revolves around the question as to how digital selves gain the affordance to be involved in a flash of hypervisibility. Such a flash could be your book or paper being mentioned in a New York Times article, or one of your digital selves trending on Twitter or Reddit, or your work being publically used as a basis for policy decisions. To increase the chance for something like that to happen, the fashioning of digital selves will have to move away from the idea that its main purpose is to disseminate work that is primarily academic. Instead, digital selves have to have messages that are simple and 'sexy' enough so that they can be shared on as many platforms and with as many audiences as possible. For this to work, the idea to just disseminate academic work is not enough, because not all academic work contains themes and results that can be shared in such a manner. The step to give digital selves the affordance for hypervisibility requires finding new research questions that are as much informed by the state of research in a field, as they are by a diffuse and only partially scientific public on digital media. It becomes more probable to formulate and perform a research program, that has its primary audience not within but outside of one's research field. While in earlier times such research programs would have had a chance to be ignored or even

\footnotetext{
8"ORCID provides a persistent digital identifier that you own and control, and that distinguishes you from every other researcher", is how the platform explains itself to researchers. The main slogan reads "distinguish yourself in three easy steps" and the short description of these steps is telling enough: "1. REGISTER: Get your unique ORCID identifier. It's free and only takes a minute, so register now! 2. USE YOUR ORCID ID: Use your iD, when prompted, in systems and platforms from grant application to manuscript submission and beyond, to ensure you get credit for your contributions. 3. SHARE YOUR ORCID iD: The more information connected to your ORCID record, the more you'll benefit from sharing your iD - so give the organizations you trust permission to update your record as well as adding your affiliations, emails, other names you're known by, and more" (orcid.org, August 6, 2020).
} 
denounced by colleagues as non-scientific (e.g. in peer review), now they are regarded with more respect and even envy, because they can provide the much sought after recognition through metrics. Since most of the metrics have no sensitivity for the source of attention - whether a retweet is from another scientist, a random digital self, or a bot is irrelevant, or whether a citation comes from within the field of expertise or from outside, is positive or negative is also irrelevant - maximizing visibility and attention from maximally diverse audiences is key.

This is the step where the limits of individual control over one's digital selves become obvious. The work of others is needed to provide mentions, likes, citations, etc. (orcid's step 3 makes this explicit) and since this is a media ecology with extremely skewed distributions of attention, the selffashioning must go to extremes. Such extremes can be in quantity, by just putting more content and a higher frequency of messages into the digital realm than others, or in quality, by simplifying messages down to the clickbait like logic of social media. Besides volume and simplicity, at least two additional strategies are possible with respect to the actual content, to increase the chance of becoming temporarily hypervisible. One is to communicate on a maximally heterogeneous set of topics. Digital selves that can speak on a variety of issues maximise the probability of being called upon when one of these issues becomes the center of a news cycle. The problem with this strategy could be that such a digital self may not become really the center of attention because for each specific topic others may be more specialized. This would then be the other strategy, to specialize on one simple message to maximize the chance of receiving center stage, when topicality arrives; in contrast to the first strategy, at the risk of that topic not becoming relevant for a long time. Irrespective of how such a strategy is put together in terms of volume, simplicity, heterogeneity, and topicality, it will run into a double constraint of time and quality. How much time can be afforded to fashion such possibly highly visible selves and how large can the tradeoff for expertise and the quality of the associated research be?

The time constraint should be easy to see, as there is little direct benefit to the quality of research that comes from creating affordances for hypervisibility. The quality constraint, however, is less obvious as there was little expectation, so far, to be penalized for work that is only average or even below average. Careers are primarily made from the rare hits, while every researcher's publication portfolio is full of contributions that have only received average or below average recognition. It is thus a plausible career strategy to increase volume at the cost of quality, to increase the chance of landing a hit. Such a strategy may, however, have come under pressure recently, because measures to ensure a minimal quality of research are more frequently discussed and sometimes implemented. Automated tools for checking for plagiarism, image manipulation, and problematic statistics are one visible measure in this context. "Statcheck" (Chawla, 2017), an algorithm for scanning large numbers of papers for unsound statistical 
analysis, can serve as a good example. When the algorithm was used to scan large numbers of papers from psychology and the results were then published on pubpeer.org, there was a controversial debate (Chawla, 2016). While much of this debate concentrated on whether the algorithm was good enough and whether it was justified to make the results public in an individualized manner on a platform that is mostly associated with misconduct, the signal to large numbers of researchers was more clear: Beware your publications will be checked, sometimes long after publication; the check will come from algorithms (also with biases and false positives); and the (negative) visibility will be automatic and carry the stigma of misconduct!

\section{HYPERVISIBILITY AS A BLESSING OR A CURSE}

The step to create affordances for hypervisibility is thus a crucial and unavoidable one. High competivity with heavily skewed distributions for recognition lead to individual strategies that strive for hypervisibility. The promise of a flash and halo visibility is, however, not a uniformly positive one. Even in the optimal case of a prestigeous prize for one's research, the burden on an individual researcher can be substantial and overwhelming (see above). What if the case is not an optimal one? What if the increased visibility also renders those parts visible of a digital self that are average or below average? What if the increased visibility comes from accusations of substandard or even fraudulent work? What if the increased visibility comes from being "different" (e.g. due to gender, age, institutional affiliation or nationality)? Even if digital selves never reach such a level of positive or negative hypervisibility, their fashioning needs to anticipate such possibilities. The question thus becomes, how to fashion a digital self that is at least partly protected against the downsides of hypervisibility? To me, this is the currently emerging question that guides the self-fashioning of researchers in decentralized panopticism.

Maximizing the chance for hypervisibility, while also limiting the negative (side-)effects, is what researchers are doing with their digital selves. For average scientists this may not (yet) be a pressing issue, that requires immediate and strategic work, but for highly visible ones, it may be different. In the middle of a flash of hypervisibility it can become crucial to find ways of protecting one's reputation, when most of the work that defines a digital self is done by many different actors on social media, in the press, or on television and, thus, mostly outside of the direct control of the researcher that embodies that digital self. A recent example for this is Christian Drosten, the most visible virologist during the Covid-19 pandemic in Germany, who became the target of a smear campaign by the German tabloid Bild: "When public impatience with closed schools and shops began to mount in late May, Bild, having failed to gain traction with its usual 
scapegoats, changed tack. Its new target was Germany's leading virologist, Christian Drosten, who had become an unexpected celebrity thanks to his measured media interviews and his advisory role to Merkel's government. On 25 May, one of Bild's reporters sent him an email, claiming that other experts had serious criticisms of his latest study on Covid-19. The reporter demanded that Drosten respond within an hour. Instead, Drosten published the email on Twitter and said there that he had 'better things to do'. The subsequent article, which tried to blow up minor statistical disagreements into a public assault on Drosten's reputation, backfired drastically. The German mediasphere rallied to his defence: \#Ichhabebessereszutun (\#betterthingstodo) became a hashtag" (Meaney, 2020). What protected Drosten in this case was that he was communicating on all platforms and media for several months to the point where it seemed that he was not doing anything else; e.g., during the first five months of the pandemic he recorded 52 podcasts, each close to 1 hour long, with a public radio station, to discuss research and policy around the pandemic. ${ }^{9}$ It seems that the sheer volume and diversity of material, that he put out into the public, allowed not just tabloids to use these for an attack but also allowed many other voices to defend him and defend him with substance. ${ }^{10}$

Average scientists may not have the pressing need of a mass media flash and halo to push the output of their digital selves to extremes, however, decentralized panopticism increasingly makes this an attractive, and preemptive, strategy. Even though hypervisibility may involve significant threats to a scientist's reputation, that come from the volume of communication needed to maintain effective digital selves, the answer to these threats seems to be to communicate even more. What has become an increasing ambivalence between competivity and meritocracy on the institutional level, is felt by individuals as the ambivalence to maximize output and to respond to the dangers of hypervisibility by increasing output even more. Feelings of anxiety and imposter syndrome might be direct effects of this ambivalence on the individal level and, institutionally, it seems that the promises of open science serve as an object to help stabilize such increasing ambivalence.

\section{OPEN SCIENCE AS A LUKEWARM UTOPIA}

Mirowski (2018) has argued that the enthusiasm for open science is misplaced as "the agenda is effectively to re-engineer science along the lines of platform capitalism, under the misleading banner of opening up science to the masses" (Mirowski, 2018, p. 171). As convincing as his account of the

\footnotetext{
${ }^{9}$ https://www.ndr.de/nachrichten/info/podcast4684_page-1.html

${ }^{10}$ Jordan Peterson is, in some ways, a similar example. He became hypervisible as a psychologist in the fierce debates over policy to protect people with non-binary gender identities. He also responded by putting out extreme volumes of lectures, interviews, and activity on social media platforms.
} 
shifting regimes in science policy is from a macro perspective, it remains unclear where the 'enthusiasm' of individual scientists for open science comes from. Being lured by "gamification” (Mirowski, 2018, p. 192) to the point of becoming blind to shifting policy regimes, makes it sound as if scientists were social, or better, political dopes. It is too simplistic to claim that the attraction e.g. of the open access movement came from the possibility of a rebellion against oligopolistic scientific publishers and that the reversal of open access as a moral veil to hide even larger profits should have gone unnoticed. Of course it has been noticed, and the initial enthusiasm has already turned towards a more desperate emotional realm. The support for open science by individual scientists seems more and more like the passive acceptance of policies that are seen as inevitable, but that might offer at least a chance of saving one's career by adjusting digital selves accordingly. What the account in this paper can add to Mirowski's argument is, thus, an explanation of why individual scientists might support open science not out of being duped by greedy corporations but out of exhaustion over escalating career requirements in decentralized panopticism.

As argued above, the balance between competitivity and meritocracy has been shifting. Combined with the insight by individual scientists that career requirements are escalating under conditions of decentralized panopticism, while it becomes obvious that long-term chances of success are slim, may prove to be an unstable mix. Feelings of anxiety and fatalism seem, thus, to be more than mere dissatisfaction with working conditions or just a sign of a 'necessary' mechanism of self-selection for those disillusioned enough to leave a scientific career. They seem also to be a sign that the promises and utopias of science have lost some of their appeal. The notoriously high level of instrinsic motivitation for scientific and societal progress through experimentation, discourse, and collective learning, seem currently less convincing. This is to say that current utopias for science are lacking, and Mirowski's case against open science makes it easy to see why. The same seems to apply to other promises and programs that science policy currently has to offer. Many follow an obviously conservative agenda that deemphasizes the excitement for radical new knowledge and profound societal change through emphasizing the need to ensure minimal levels of research quality (avoid scientific misconduct, enhance good scientific practice, etc.), to promote responsibility (responsible research and innovation), or to apply existing knowledge instead of creating new knowledge (transfer, translation, impact) (Flink \& Kaldewey 2018, Flink \& Peter 2018). Where the agenda is more progressive by promoting openness (open science, open innovation, transparency), or by declaring grand challenges (UN sustainable development goals), or by fostering excellence, the utopias appear as so out of touch with the experience of individual careers, that fatalism and anxiety are the appropriate reactions.

Two examples may illustrate this point: When we interviewed biomedical researchers in Switzerland in 2018, where working conditions, 
career opportunities, and level of research are believed to be among the best in the world, a conspicuous narrative emerged (Hendriks, Schendzielorz and Reinhart, 2018). We asked about funding and career opportunities and in the light of decreasing funding rates and increasing competitivity, some respondents began to develop a narrative defending average scientists and average scientific work against the ever present demand for excellence. This narrative boils down to the complaint that science policy under the rubric of excellence has increased competitivity to the point where doing average and good work is exeedingly difficult and then defending that average good work as a necessary precondition for excellent work. The second example comes from a series of events and conferences that I have attended over the last five years in the field of meta-research. Meta-research has emerged in biomedicine as a form of science studies that addresses issues of research quality and translation. Much of the work in this field is geared towards improving e.g. the reproducibility of studies or the use of animals in research. A conspicuous narrative that runs through these events and conferences (more so than in the published literature) is the understanding that younger scientists endanger their careers when they want to become the forefront of a culture change in improving research quality. Most memorable was a situation during the Q \& A after a ceremonial talk by the most visible senior figure in this field who emphatically demanded more robust research practices, when multiple younger scientists challenged his authority by also emphatically illustrating the everyday burden these demands posed on their careers. One of them invoked the image of the senior figures in the field being large and healthy trees while the younger researchers (one is tempted to say: activists) are mere grass that is withering. It was unclear whether the image implied that the withering is a result of the shade of the big trees or the crowding out from grass that grows in the sun, but I believe that both were implied.

When competitivity is seen as driving out average, solid work and when meritocracy is seen as not rewarding average, solid work, then, it must seem to researchers that the institutional basis for science has become counterproductive. An idealistic image of science becomes difficult to uphold, when the chances for individual success seem slim and unjustly distributed, and when decentralized panopticism feels like a lottery where chasing hypervisibility is the equivalent of acquiring just more lottery tickets (Reinhart and Schendzielorz, 2020). It should come as no surprise that attempts from science policy to mobilize institutional change through a plethora of concepts and utopias (open science, responsible research and innovation, translation, etc.) receive only lukewarm support. To scientists they must seem like passing fads with which one must associate enough to further one's career, but not too much to still be able to catch the wave of the policy concept that comes next. Among them, it seems, that open science is the only current policy agenda, that at least offers some perspective for individual careers: you make as much of your work visible (and not 
necessarily accessible) as possible, you prepare your digital selves for hypervisibility, and hope that you get lucky. All the other agendas have little to offer to individual scientists, as they do not address the shifting ambivalence between competitivity and meritocracy and as they limit the possibilities for the visible fashioning of digital selves.

\section{CONCLUSION}

Ideals of competitivity and meritocracy are deeply engrained in how researchers feel and think about science. Scientists show a high level of intrinsic motivation because these ideals connect individual contributions to the collective advancement of knowledge in a non-ambivalent way: Science contributes to society by advancing knowledge and scientists are rewarded roughly according to their individual contribution to this collective goal. These ideals, however, have become more difficult to uphold in the context of a visibility regime of decentralized panopticism that results from shifts to digital forms of communication and platform cultures. Scientists are increasingly competing for career opportunities not just through contributions to the advancement of knowledge but through the fashioning of digital selves, albeit with the intent of drawing attention to such contributions. This seems to result in more ambivalent views of the ideals of competitivity and meritocracy, as feelings of anxiety, 'impostor syndrome', and fatalism have become part of collective sensemaking. The explanation offered in this essay for this phenomenon rests not on a mechanistic view that would see this as a predictable result of hypercompetitivity or of normalizing tendencies in panoptic visibility regimes. Rather, it is individual scientists making sense of their increasingly demanding work of fashioning digital selves and of the platform-based feedback this work elicits. Their challenge rests in coping with an unveiling suspicion that fashioning digital selves leads them farther from actually contributing to the advancement of knowledge and that their visibility is mostly relevant for platforms and indicators. As a result, the excitement over the possibilities for attaining hypervisibility is taken over by anxiety over being exposed to the possibility of negative, reputation-threatening attention. Pardoxically, anticipating and preventing such a possibility leads to even more vigorous fashioning of digital selves, for which the open science movement, at the moment, provides the most convenient policy narrative.

Admittedly, the main argument of this essay is overly pessimistic, as it has little to say about how scientists find meaning and motivation in digital, platform-based communication. Nonetheless, it is a necessary exercise to explore the pronounced swing in idealistic attitudes over the last decades, because the intrinsic motivation of scientists seemed unshakeable for a long time, despite slim chances for long-lasting careers and despite the sometimes painstaking work to make even small contributions. While these chances have changed little, the change in attitude must be the result of something 
else, and the visibility regime of a decentralized panopticon is a likely explanatory candidate. While I have explored here how scientists may cope emotionally with these developments, the political consequences have only been touched upon lightly. A shift in idealistic attitudes and an emotional turn towards anxiety and fatalism will also create new scope for social movements to change scientific cultures. So far, however, such movements seem to be neutralized quickly by an ever shifting and expanding policy landscape that seems to have concepts, ideals, and utopias for every occasion. Maybe the time has come to think about science as field that can serve as a case to investigate whether and how social movements, resistance, and cultural change are possible under decentralized panopticism. 
Bibliography

Barbalet, J. M. (2004) Emotion, Social Theory \& Structure: A

Macrosociological Approach. Cambridge University Press.

Bezzola Lambert, L. (2016) 'Repetition with a Difference: Reproducibility in Literature Studies', in Atmanspacher, H. and Maasen, S. (eds)

Reproducibility: Principles, Problems, Practices, and Prospects. Hoboken, NJ: Wiley, pp. 491-509.

Blümel, C. et al. (2015) In search of translational research. iFQ-BIHReport. Berlin Institute of Health.

Böhler, F. and Reinhart, M. (2014) 'Wissenschaft und Wertewandel', in Bischoff, C., Oehme-Jüngling, K., and Leimgruber, W. (eds) Methoden der Kulturanthropologie. Bern: Haupt Verlag, pp. 539-556.

Brighenti, A. (2007) 'Visibility: A Category for the Social Sciences', Current Sociology, 55(3), pp. 323-342.

Brighenti, A. (2010) Visibility in social theory and social research.

Basingstoke; New York: Palgrave Macmillan.

Brighenti, A. M. (2019) 'Umwelt-measures. On extensive and intensive measures: Introduction to the special issue "Theorising measures, rankings and metrics”', Social Science Information, 58(2), pp. 224-237.

Chawla, A. D. S. (2016) 'Psychological society wants end to posting errorfinding algorithm results publicly’, Retraction Watch, 25 October. Available at: https://retractionwatch.com/2016/10/25/psychological-society-wants-endto-posting-error-finding-algorithm-results-publicly/ (Accessed: 25 July 2020).

Chawla, D. S. (2017) Controversial software is proving surprisingly accurate at spotting errors in psychology papers, Science |AAAS. Available at: https://www.sciencemag.org/news/2017/11/controversial-softwareproving-surprisingly-accurate-spotting-errors-psychology-papers (Accessed: 10 August 2020).

Dalen, H. P. van and Henkens, K. (2012) 'Intended and unintended consequences of a publish-or-perish culture: A worldwide survey', Journal of the American Society for Information Science and Technology, 63(7), pp. 1282-1293.

Daston, L. (2000) Eine kurze Geschichte der wissenschaftlichen Aufmerksamkeit. München: Carl Friedrich von Siemens Stiftung.

Daston, L. and Galison, P. (2007) Objectivity. New York: Zone Books.

Desrosières, A. (1998) The politics of large numbers: A history of statistical reasoning. Cambridge, Mass: Harvard University Press.

Espeland, W. N. and Sauder, M. (2016) Engines of Anxiety: Academic Rankings, Reputation, and Accountability. New York, New York: Russell Sage Foundation. 
Flink, T. and Kaldewey, D. (2018) 'The new production of legitimacy: STI policy discourses beyond the contract metaphor', Research policy, 47(1), pp. 14-22.

Flink, T. and Peter, T. (2018) 'Excellence and Frontier Research as Travelling Concepts in Science Policymaking’, Minerva, 56(4), pp. 431-452.

Fochler, M., Felt, U. and Müller, R. (2016) ‘Unsustainable Growth, HyperCompetition, and Worth in Life Science Research: Narrowing Evaluative Repertoires in Doctoral and Postdoctoral Scientists' Work and Lives', Minerva, 54(2), pp. 175-200.

Foucault, M. (1977) Discipline and Punish: The Birth of the Prison. New York: Vintage.

Franssen, T. et al. (2018) 'The Drawbacks of Project Funding for Epistemic Innovation: Comparing Institutional Affordances and Constraints of Different Types of Research Funding', Minerva, 56(1), pp. 11-33.

Gabriel, Y. (2010) 'Organization studies: A space for ideas, identities and agonies’, Organization Studies, 31(6), pp. 757-775.

Garland, D. (1986) 'Foucault’s Discipline and Punish-An Exposition and Critique’, Am. B. Found. Res. J., p. 847.

Giddens, A. (1990) The Consequences of Modernity. Cambridge: Polity Press.

Greenblatt, S. (1980) Renaissance Self-Fashioning. Chicago: The University of Chicago Press.

Grey, P. (2020) 'Four tips to ward off impostor syndrome', Nature. doi: 10.1038/d41586-020-02408-z.

Haampland, O. (2017) 'Power Laws and Market Shares: Cumulative Advantage and the Billboard Hot 100', Journal of New Music Research, 46(4), pp. 356-380.

Hearn, J. (2008) 'Feeling out of place? Towards the transnationalizations of emotions', The emotional organization: Passions and power, pp. 184-201.

Hendriks, B., Schendzielorz, C. and Reinhart, M. (2018) 'Förderung und Evaluation der Forschung in den Lebenswissenschaften in der Schweiz eine Interviewstudie.', in The growth of science: Auswirkungen für die Forschungsevaluation und -förderung in der Schweiz. Politische Analyse und Empfehlungen des Schweizerischen Wissenschaftsrates SWR. Bern: Swiss Science Council, pp. 55-99.

Hesselmann, F. et al. (2017) 'The visibility of scientific misconduct: A review of the literature on retracted journal articles', Current Sociology, 65(6), pp. 814-845. 
Hesselmann, F. (2018a) 'Punishing crimes of the mind: Sanctions for scientific misconduct as a case for the cultural theory of punishment', Theoretical Criminology, p. 527-544.

Hesselmann, F. (2018b) 'Science and its Others: examining the discourse about scientific misconduct through a postcolonial lens', Identities, 26(4), pp. 393-411.

Hesselmann, F. and Reinhart, M. (2019) 'Science Means Never Having to Say You're Sorry? Apologies for Scientific Misconduct', Science Communication, 41(5), pp. 552-579.

Hesselmann, F. and Reinhart, M. (2020) 'Cycles of Invisibility: The Limits of Transparency in Dealing with Scientific Misconduct', Social Studies of Science. Online First: https://doi.org/10.1177\%2F0306312720975201.

Ioannidis, J. P. A. (2005) 'Why Most Published Research Findings Are False’, PLOS Med, 2(8), p. e124.

Keogh, M. (2020) 'How to shake off the "impostor" fears that plague your PhD studies’, Nature. doi: 10.1038/d41586-020-02401-6.

Kim, L. et al. (2020) 'The Influence of Changing Marginals on Measures of Inequality in Scholarly Citations: Evidence of Bias and a Resampling Correction', Sociological Science, 7, pp. 314-341.

Knights, D. and Clarke, C. A. (2013) 'It's a Bittersweet Symphony, this Life: Fragile Academic Selves and Insecure Identities at Work:’, Organization Studies, 35(3), pp. 335-357.

Latour, B. and Woolgar, S. (1986) Laboratory Life: The Construction of Scientific Facts. 2nd Edition with a New Postscript. London: Sage Publications.

Loveday, V. (2018) “'Luck, chance, and happenstance? Perceptions of success and failure amongst fixed-term academic staff in UK higher education”', The British Journal of Sociology, 69(3), pp. 758-775.

Lovink, G. (2014) Das halbwegs Soziale: Eine Kritik der Vernetzungskultur. transcript Verlag.

Luhmann, N. (2000) Vertrauen: Ein Mechanismus der Reduktion sozialer Komplexität. Stuttgart: UTB.

Luppicini, R. (2012) Handbook of Research on Technoself: Identity in a Technological Society: Identity in a Technological Society. IGI Global.

Maasen, S. and Sutter, B. (2016) 'Dezentraler Panoptismus', Geschichte und Gesellschaft, 42(1), pp. 175-194.

Meaney, T. (2020) 'Bild, Merkel and the culture wars: the inside story of Germany's biggest tabloid', The Guardian, 16 July. Available at: https://www.theguardian.com/world/2020/jul/16/bild-zeitung-tabloid-julianreichelt-angela-merkel-germany (Accessed: 20 July 2020). 
Merton, R. K. (1968) 'The Matthew Effect in Science’, Science, 159(3810), pp. 56-63.

Merton, R. K. (1973) The Sociology of Science: Theoretical and Empirical Investigations. University of Chicago Press.

Mirowski, P. (2018) 'The future(s) of open science', Social Studies of Science, 48(2), pp. 171-203.

Reinhart, M. (2012) Soziologie und Epistemologie des Peer Review. BadenBaden: Nomos.

Reinhart, M. (2016) 'Reproducibility in the Social Sciences', in Atmanspacher, H. and Maasen, S. (eds) Reproducibility: Principles, Problems, Practices, and Prospects. Hoboken, NJ: Wiley, pp. 407-423.

Reinhart, M. and Schendzielorz, C. (2020) 'The lottery in Babylon-On the role of chance in scientific success', Journal of Responsible Innovation, 7(sup2), pp. S25-S29. doi: 10.1080/23299460.2020.1806429.

Rijcke, S. de et al. (2016) 'Evaluation practices and effects of indicator use-a literature review', Research Evaluation, 25(2), pp. 161-169.

Sauder, M. and Espeland, W. N. (2009) 'The Discipline of Rankings: Tight Coupling and Organizational Change', American Sociological Review, 74(1), pp. 63-82.

Schendzielorz, C. and Reinhart, M. (2020) 'Die Regierung der Wissenschaft im Peer Review / Governing Science Through Peer Review', dms - der moderne staat - Zeitschrift für Public Policy, Recht und Management, 13(1), pp. 101-123.

Shapin, S. (1994) A Social History of Truth: Civility and Science in Seventeenth-Century England. University Of Chicago Press.

Shapin, S. and Schaffer, S. (1985) Leviathan and the Air-Pump: Hobbes, Boyle, and the Experimental Life. Princeton University Press.

Thomas, W. I. and Thomas, D. S. (1928) The Child in America. New York: Knopf.

Thompson, J. B. (2005) 'The New Visibility', Theory, Culture \& Society, 22(6), pp. 31-51.

Torka, M. (2009) Die Projektförmigkeit der Forschung. Baden Baden: Nomos.

Torka, M. (2018) 'Projectification of Doctoral Training? How Research Fields Respond to a New Funding Regime’, Minerva, 56(1), pp. 59-83.

Weber, M. (2002) 'Wissenschaft als Beruf', in Schriften 1894-1922. Stuttgart: Kröner, pp. 474-511. 
Weingart, P. (1999) 'Scientific expertise and political accountability:

paradoxes of science in politics', Science and Public Policy, 26(3), pp. 151161.

Zuckerman, H. (1967) 'Nobel Laureates in Science: Patterns of Productivity, Collaboration, and Authorship', American Sociological Review, 32(3), pp. 391-403. 